\title{
Aa. Vv., «Cultures Sud», Retours sur la question coloniale
}

\section{Maria Chiara Gnocchi}

\section{(2) OpenEdition}

1 Journals

Édition électronique

URL : http://journals.openedition.org/studifrancesi/9351

DOI : 10.4000/studifrancesi.9351

ISSN : 2427-5856

Éditeur

Rosenberg \& Sellier

\section{Édition imprimée}

Date de publication : 1 juin 2008

Pagination : 228-229

ISSN : 0039-2944

\section{Référence électronique}

Maria Chiara Gnocchi, «Aa. Vv., «Cultures Sud», Retours sur la question coloniale », Studi Francesi [En ligne], 154 (LII | I) | 2008, mis en ligne le 30 novembre 2015, consulté le 13 janvier 2021. URL : http:// journals.openedition.org/studifrancesi/9351; DOI : https://doi.org/10.4000/studifrancesi.9351

Ce document a été généré automatiquement le 13 janvier 2021.

\section{(c) $(1) \&$}

Studi Francesi è distribuita con Licenza Creative Commons Attribuzione - Non commerciale - Non opere derivate 4.0 Internazionale. 


\title{
Aa. Vv., «Cultures Sud», Retours sur la question coloniale
}

\author{
Maria Chiara Gnocchi
}

\section{RÉFÉRENCE}

«Cultures Sud», Retours sur la question coloniale, 165, avril-juin 2007, pp. 173.

1 La colonisation serait, selon la définition de l'historien Gilles MANCERON, «un passé que la France a du mal à regarder en face». Pendant la seconde moitié du $\mathrm{xx}^{\mathrm{e}}$ siècle, le silence a plané sur ce sujet, exception faite pour le retour, dans les années 1980, aux débats concernant le problème de la torture durant la guerre d'Algérie; nous assistons en revanche, dans ce début $d u \mathrm{XXI}^{\mathrm{e}}$ siècle, à de multiples «retours du colonial». Les événements les plus importants se situent entre 2005 et 2006: c'est d'abord le débat sur la loi du 23 février 2005, visant à la reconnaissance du «rôle positif de la colonisation» dans les manuels d'histoire; ensuite la crise des banlieues, pendant l'hiver de cette même année, qui permet (paradoxalement?) à plusieurs générations d'immigrés de s'exprimer; enfin, en 2006, la sortie, le succès et la consécration du film Indigènes de Rachid Bouchareb, dédié aux soldats africains ayant participé à la Seconde Guerre mondiale.

2 Parler de «retour(s)» présuppose bien entendu la persistance d'un tabou, voire d'un déni, à la fois reconnu et dépassé par le retour lui-même. C'est à ce dépassement que visent les nombreux articles qui composent ce numéro de «Cultures Sud». L'essentiel du volume est consacré aux dimensions et aux implications historiques du «retour de la question coloniale»: la parole est donnée à différents historiens qui se penchent depuis longtemps - et avec le plus grand profit - sur ce sujet, comme Nicolas BANCEL, Pascal BLANCHARD et Gilles MANCERON, déjà cité. Une première section «historique» est consacrée aux «Patrimoines controversés» et donc, par exemple, au difficile processus de mise en patrimoine de l'espace colonial (Alain SINOU), ou encore à la «nouvelle guerre des mémoires» qui s'est déchaînée en France à la suite de la proposition de loi 
du 23 février 2005 (Pascal Blanchard). Une deuxième section «historique» suit, intitulée «Mémoire, histoire coloniale et postcoloniale»: elle accueille entre autres un compte rendu de la contribution des historiens africains à l'historiographie de l'Afrique des $\mathrm{XIX}^{\mathrm{e}}$-XX $\mathrm{X}^{\mathrm{e}}$ siècles, par Pierre KIPRÉ, une étude des histoires et mémoires de l'esclavage dans les pays français d'outre-mer, par Françoise VERGÈs, et une analyse du poids de la guerre d'Algérie dans les représentations mémorielles les plus récentes (2006-2007) du temps colonial, par Benjamin STORA.

Les «Regards littéraires» interviennent seulement dans la troisième section. C'est Bernard MOURALIS qui l'ouvre, par un article où il analyse le traitement du fait colonial dans la littérature africaine des dernières décennies. En effet, si la référence à la colonisation a été un thème essentiel dans la littérature africaine des années 1920 à 1960, on peut se demander si et comment les écrivains de la période postérieure aux indépendances s'intéressent à cette question. L'étude de quelques œuvres d'Amadou Hampâté Bâ, de Valentin-Yves Mudimbe, de Tierno Monénembo, de Mongo Beti et d'Ahmadou Kourouma permet à Mouralis de conclure que les œuvres les plus récentes de ces auteurs révèlent «un désir d'analyse beaucoup plus qu'un travail mémoriel, qui se traduit, en particulier, par l'absence de sentiment de culpabilité ou de mauvaise conscience»; cette attitude caractérise surtout, on le devine, les plus jeunes écrivains (p.98). Dans l'article suivant, Romouald-Blaise fonKouA aborde la littérature des «invisibles», à savoir la littérature de la banlieue. L'auteur la considère comme une nouvelle catégorie dont la genèse recoupe l'histoire des différentes littératures de langue française, et qui prend place à la suite des écritures de la seconde moitié du $\mathrm{xx}^{\mathrm{e}}$ siècle dont les histoires se déroulent dans les bas-fonds de Paris (de Zazie dans le métro de Raymond Queneau aux policiers de Léo Malet, en passant par les noirs de Didier Daeninckx ou par les romans de la condition ouvrière moderne). Fonkoua propose, en clôture de son étude, une bibliographie indicative d'une vingtaine d'œuvres très récentes, datant presque toutes d'après l'an 2000. Olivier BARLET, spécialiste de cinémas d'Afrique (et président de l'association Africultures), se concentre, quant à lui, sur «Le tirailleur au cinéma»: il analyse le phénomène Indigènes tout en reconnaissant le combat mené par nombre de cinéastes qui, avant Rachid Bouchareb, ont rappelé sur l'écran l'effort des tirailleurs et des goumiers au service de l'armée française. Les titres les plus récents cités par Barlet témoignent d'un même militantisme et d'une même lecture idéologique des faits narrés: ainsi La Dette, téléfilm de Fabrice Cazeneuve (2002), La Reconnaissance, film de Didier Bergounhoux et de Claude Hivernon (2005), et le documentaire La Couleur du sacrifice, de Mourad Boucif (2006). La section littéraire se conclut par un article de Jean-Claude CARPANIN MARIMOUTOU sur les littératures postcoloniales de la créolisation, par une étude sur «Théâtre, décolonisation et engagement en Afrique subsaharienne» et par un entretien avec Leïla SEBBAR intitulé «Entre exil et enracinement» (propos recueillis par Boniface MONGo-MBousSA). De nombreux volumes récents sont signalés dans la section relative aux notes de lecture, ayant un sujet très proche de celui de ce numéro de «Cultures Sud»: signalons Romain Bertrand, Mémoire d'empire. La controverse autour du «fait colonial» (2006), Éric Deroo et Antoine Champeaux, La Force noire. Gloire et infortunes d'une légende coloniale (2006), un numéro de «Politique africaine» sur les «Passés coloniaux recomposés» $(n .102,2006)$ et un numéro de «Francofonía» (Cádiz) sur René Maran (n. 14, 2005).

4 La lecture de ce volume est fort recommandée à un public beaucoup plus vaste que celui des chercheurs concernés par la question coloniale: les grands spécialistes qui y 
ont contribué dressent un bilan important de l'historiographie du xxe siècle, et ouvrent de nouvelles pistes de lecture qui peuvent s'appliquer à la fois à l'histoire, à la littérature, au cinéma et à l'actualité dans toute sa diversité. 